\title{
Residential Parking in Vibrant City Districts
}

by

Inga Molenda and Gernot Sieg

Institute of Transport Economics Münster

Working Paper

No. 18

September 2013 
(c) Westfälische Wilhelms-Universität (WWU), Institute of Transport Economics, 2013

\section{Address}

Institut für Verkehrswissenschaft

Am Stadtgraben 9

D 48143 Münster, Germany

Telephone

+4925183-22994

Fax

$+4925183-28395$

\section{E-Mail}

verkehrswissenschaft@uni-muenster.de

\section{Website}

http://www.iv-muenster.de

All rights reserved.

Any reproduction, publication and reprint in the form of a different publication, whether printed or produced electronically, in whole or in part, is permitted only with the explicit written authorisation of the Westfälische Wilhelms-Universität, Institute of Transport Economics, or the author(s).

The views expressed in this paper do not necessarily reflect those of the Institute of Transport Economics or the WWU.

The Working Paper Series seeks to disseminate economic research work by the WWU, Institute of Transport Economics staff and visitors. Papers by researchers not affiliated with the WWU Institute of Transport Economics may also be considered for publication to the extent that they have been presented at research seminars/workshops organised by the institute.

The working papers published in the Series constitute work in progress circulated to stimulate discussion and critical comments. Views expressed represent exclusively the authors' own opinions.

The Series is managed by the Director of the Institute of Transport Economics. 


\title{
Residential Parking in Vibrant City Districts
}

\author{
By Inga Molenda and Gernot Sieg*
}

\begin{abstract}
Living downtown can be advantageous because it enables convenient access to a variety of shopping and leisure activities, but a major disadvantage is the difficulty of finding a parking spot. We formally model the trade-off between privileged parking for residents and economic vitality in terms of the product variety available in a vibrant city district and identify situations in which assigning on-street parking spaces to residential parking is an optimal policy, both from a welfare and a resident perspective. We demonstrate that privileged parking for residents is unlikely to constitute a first best policy with regard to parking cost minimization and ensuring an efficient level of economic vitality.

JEL:R41; R48; D61; D72

Keywords: residential parking, urban vitality, love of variety, local decision-making
\end{abstract}

Downtown areas and other vibrant districts of European cities are often both commercial and residential areas. Residents, a variety of retail stores and restaurants, and visitors from outside the district all add to the vibrancy. For car drivers, the downside of living in, working in, or visiting such a district is the struggle to find an individually suitable parking spot. Because many downtown areas and their surrounding districts of European cities were developed when car ownership was not nearly as common as it is nowadays, residents often lack sufficient private parking capacity, so that they are dependent on public parking spaces. Residents usually experience a high disutility from searching for a parking spot in "their" neighborhood and from possibly not being able to park close to their homes, so they often favor parking regulations that privilege them. However, residents of vibrant city districts normally also enjoy the variety of stores and restaurants in their neighborhood and they know that non-resident customers are relevant to the variety offered and that parking policies such as the establishment of resident parking areas can influence their visits negatively.

Still and Simmonds (2000) report results from both attitudinal studies and land-use/transport models supporting the argument that the economic vitality of urban centers is sensitive to the provision of parking. They emphasize the concerns local authorities often have when deciding on parking policies: retailing is important to local residents, and maintaining the economic vitality of urban centers also depends on shoppers from outside as well.

A non-resident visits a vibrant city district to shop, if the associated private benefit exceeds the associated private cost. In a setting where more shoppers add to variety that also benefits other people, but also induce a parking cost increase, due to more competition for a suitable parking spot, either too many or too few non-residents might visit the district at an unregulated (free on-street parking)

* Molenda: WWU Münster, Institut für Verkehrswissenschaft, Am Stadtgraben 9, 48143 Münster, inga.molenda@uni-muester.de. Sieg: WWU Münster, Institut für Verkehrswissenschaft, Am Stadtgraben 9, 48143 Münster, gernot.sieg@uni-muenster.de. Acknowledgements: We thank Jos van Ommeren, Mogens Fosgerau, two anonymous referees, Ulrich van Suntum, Aloys Prinz and the participants of the 2013 Kuhmo NECTAR Conference for helpful comments and suggestions. 
equilibrium, depending on the magnitude of the overall external effect.

Assuming the absence of further market distortions, both the aggregate parking costs are minimized and the number of non-resident shoppers is optimal in a firstbest solution. We will show that parking fees/subsidies and self-selection may lead to a first-best solution in a model with two types of consumers (residents and nonresidents) and two parking facilities (on-street and a parking lot). For several reasons, however, the first-best solution might not feasible. Parking subsidies may provoke undesired behavior, such as visits by non-residents wishing to earn the subsidy, but with no intention to shop. Furthermore, self-selection through second degree price differentiation may be impossible if the residents and/or the non-residents differ in their preference for product variety and the cost of parking. Besides, if it is optimal that residents pay for parking in theory, it is unlikely that they do so in reality, either because of their lobbying efforts or because of urban development measures.

If residents have privileges on public parking capacities, municipalities apply some kind of a residential parking policy. In Germany, for example, there are basically two different residential parking policies: the residents are either exempted from paying the usually charged parking fees or they are exclusively entitled to use a specific share of on-street parking spaces, such as all parking spaces on one side of the road. In both cases, the residents need a residential parking permit that is issued by the municipal road traffic departments for an administrative fee of about $30 €$ per annum. ${ }^{1}$ Important to note is that such a permit gives a special parking right to the holder, but does not guarantee that there will be a parking space available.

In our analysis, we discuss a residential parking policy according to which a certain share of on-street parking spaces is reserved for residents as an alternative to the first-best policy that might prove elusive. We reveal under which circumstances assigning on-street spaces to residential parking would be reasonable in principle. Furthermore, taking into account that there is a trade-off between parking privileges for residents and economic vitality in terms of the product variety offered and valued by residents and visitors, we determine the optimal share of residential parking spaces. Additionally, because parking policies are decided on a local level and local voters are residents (Arnott, 2011), we further analyze the optimal share of on-street spaces allocated to residential parking from the resident perspective only and we find that it exceeds what is optimal from the welfare perspective. With regard to meeting the two objectives of minimizing aggregate parking costs and ensuring an efficient number of non-resident shoppers, such a residential parking policy is certainly inferior to the first-best policy.

Since transport economists recognized that parking is a crucial element of urban transportation, parking has received increasing attention in the economic literature. Willson (1995) and Shoup (1999, 2005) discuss planning standards such as minimum parking requirements with regard to urban sprawl, automobile use, and the accompanying social costs. Furthermore, many publications address cruising for on-street parking in downtown areas, both in isolation and in the context of general traffic congestion as well as both in the absence and in the presence of an private off-street market (e.g., Glazer and Niskanen (1992); Arnott and Rowse (1999, 2009); Anderson and de Palma (2004); Shoup (2005);

\footnotetext{
${ }^{1}$ Applicants for residential parking permits have to meet a number of requirements. For example, they normally have to be the owner of the car for which the permit is valid, they can apply for one permit only or they must not have a private parking space.
} 
Calthrop and Proost (2006); Arnott and Inci (2006)). These studies recommend parking fees that reflect the social cost of parking as an efficient solution, at least if there is no off-street market. In the presence of an off-street market, adjusting the on-street parking fee to the off-street price is found to be beneficial, since it reduces cruising for parking. This positive effect is empirically observed by van Ommeren, Wentink and Rietveld (2012) for the Netherlands, where parking fees on- and off-street are quite similar. To overcome the opposition of different parties that arises when the introduction of, or an increase in, on-street parking fees is discussed, Shoup (2005, p. 398) proposes the implementation of benefit districts where the parking revenue "is spent to clean the streets, plant street trees [...] and ensure public safety." In this context, he also addresses residential parking by contrasting the establishment of pure residential parking districts with a parking policy that "taxes foreigners living abroad", while residents park for free. Van Ommeren et al. (2011) emphasize the inefficiencies that can result from such a policy. For the residents of Amsterdam, they estimate a marginal willingness to pay of about $10 €$ per day and find that it exceeds the actual tariff for a permit considerably, but that it is lower than the parking fee that non-residents pay, which implies an inefficient use of parking spaces. They also point to the further efficiency losses due to cruising for parking when the fee that non-residents pay for parking can be assumed to reflect the social parking cost. To the best of our knowledge, however, residential parking has not yet been analyzed in the context of the trade-off between parking cost minimization and the value attached to product variety offered in a city district that accommodates both residents and different types of businesses.

\section{Model}

We consider a city's vibrant residential and commercial district located at 0 on a $[0,1]$ interval. The residents are homogeneous and denoted by $r$. The number of residents is fixed and normalized to 1 . The stores located in the district are denoted by $s$. Outside the district, non-residents, the mass of which is also normalized to 1 , live uniformly distributed on the $[0,1]$ interval.

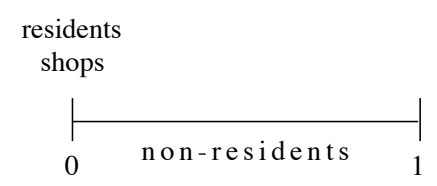

Figure 1. Spatial model Structure

\section{Stores and Product Variety.}

Each store offers one variant of a differentiated product. Although products are heterogeneous, we assume that each store sells a unit of its product at the exogenously given price $p$. We further assume that the stores have a homogeneous cost structure. Marginal cost is zero, but each store incurs an entry cost $\epsilon=E(s)$, which rises the more stores enter the district $\left(\epsilon^{\prime}=d E / d s>0\right)$, at either a constant or an increasing rate $\left(\epsilon^{\prime \prime} \geq 0\right)$. Such an assumption can be justified by the district's limited spatial capacity and the ensuing difficulties in finding an adequate location the more stores enter. 
Both residents and non-residents value product variety and each resident and each non-resident who visits the district buys one unit of each product offered. The number of visiting non-residents is denoted by $v$, so that the profit function of each store $i$ is

$$
\Pi=\Pi_{i}(v, E(s))=p \cdot[1+v]-E(s) .
$$

A store $i$ operates in the district if $\Pi \geq 0$. For the marginal entrant, $\Pi=0$ holds, so that there is no more entry as soon as $p \cdot[1+v]=E(s)=\epsilon$ applies. By means of the inverse function of $\epsilon=E(s), s=E^{-1}(\epsilon)$, we find the zero-profit number of stores to be a function of the number of visitors

$$
s(v)=E^{-1}(\epsilon)=E^{-1}(p \cdot[1+v])
$$

with $d s / d v=p \cdot\left[E^{-1}\right]^{\prime}=p / E^{\prime}>0$ and $d^{2} s / d v^{2}=-p \cdot E^{\prime \prime} /\left[E^{\prime}\right]^{3} \leq 0$.

The net utility that a resident or a visiting non-resident gains from shopping or, more generally, from the variety offered in the district is $\tilde{u}_{j}(s)$ with $j=r, n r .^{2}$ We assume that it is $\tilde{u}_{j}(0)=0$ and that the marginal utility gained from the variety provided by an additional store is constant or decreasing positive; thus it is $d \tilde{u}_{j} / d s>0$ and $d^{2} \tilde{u}_{j} / d s^{2} \leq 0$. Furthermore, as the number of stores, and with that the product variety, increases when an additional non-resident decides to visit the district, his or her decision involves a positive external effect. Thus, formally, it is $\tilde{u}_{j}(s(v))$ with $d \tilde{u}_{j} / d v=d \tilde{u}_{j} / d s \cdot d s / d v>0$.

\section{Travel Cost.}

When traveling to the district, non-residents bear per-unit car travel cost of $t$. We assume that non-residents have no alternative to traveling by car and that they do not carpool, but travel alone.

\section{Parking CAPACity and Costs.}

We assume that each resident owns a car, but does not have a private parking space. Thus, both residents and visiting non-residents have two possible ways to park their cars in the district: either on-street in direct proximity to the residential houses and stores or in a public parking lot, which is assumed to be slightly further away from the residential houses and stores. ${ }^{3}$ Because of that, residents and visitors do not consider the parking options as perfect substitutes. In fact, we assume that a driver $j=r, n r$ does not face costs when parking onstreet, but that a resident bears a cost of $c_{r}$ and a non-resident who visits the district a cost of $c_{n r}$ when parking in the lot. These costs $c_{r}$ and $c_{n r}$ comprise the driving cost to the parking lot and the walking cost to the residential houses and stores and back again.

We assume that the provision of the parking capacities does not entail costs. The number of on-street parking spaces $x_{o}$ is fixed and normalized to 1 . For the parking lot's capacity $x_{l}$, we assume $x_{l} \geq 1$. Both capacities combined, there is sufficient parking space for all potential parkers. We do not account for a

\footnotetext{
${ }^{2}$ We neglect $p$ as a function argument, since $p$ is exogenous.

${ }^{3}$ Employees working at the districts' different stores are assumed to demand neither on-street nor off-street parking.
} 


\begin{tabular}{|c|}
\hline $\begin{array}{l}\text { residents } \\
\text { stores } \\
\text { on-street parking }\end{array}$ \\
\hline parking lot \\
\hline
\end{tabular}

Figure 2. Structure of City District located at 0

temporal variation in demand, but assume that residents and visitors arrive at the district at the same time. In the absence of any parking regulations, a driver $j=r, n r$ finds an on-street space by a random-rationing rule, as in Calthrop and Proost (2006). The probability of finding a vacant on-street space is

$$
\rho=\frac{x_{s}}{r+v}=\frac{1}{1+v} .
$$

We assume that the municipality has implemented an efficient parking guidance system and that there is sufficient road capacity. Thus, cruising for parking (e.g. Glazer and Niskanen (1992); Arnott and Rowse (1999, 2009); Anderson and de Palma (2004); Shoup (2005); Arnott and Inci (2006)) or the accompanying social cost are not considered in our model.

From equation (3), it becomes obvious that there are excactly enough on-street spaces available for all residents' cars in the case of $v=0$, so that a resident has a $\rho=1$ probability of finding an on-street spot. However, rivalry in consumption emerges if $v>0$. In this case, each driver $j=r, n r$ in the district faces a $1-\rho>0$ probability of having to park in the lot of and expects a parking cost of

$$
p c_{j}(v)=c_{j} \cdot[1-\rho]=c_{j} \cdot\left[\frac{v}{1+v}\right] \text { with } \frac{d p c_{j}}{d v}=\frac{c_{j}}{[1+v]^{2}}>0 .
$$

Thus, the visit of an additional non-resident not only involves a positive, but also a negative external effect, since it leads to an increase in both the parking cost that a resident and a visitor expects.

In what follows, we discuss two parking regimes, namely the regimes $p f$ (for "parking fees") and $r p$ (for "residential parking") with regard to their ability to ensure both an optimal allocation of on-street parking spaces and an optimal number of visitors $v^{*}$. The regime $p f$ constitutes the benchmark, but our focus in this paper lies on regime $r p$. For reasons of clarity and comprehensibility, the explicit design of each parking regime $k=p f, r p$ is directly explained before its analysis. Note at this point only that, dependent on the applied parking regime $k$, each resident incurs a full parking cost of $p c_{r, k}$ and each visitor of $p c_{n r, k}$.

\section{Overall and Aggregate Utilities.}

In summary, each resident receives an overall utility from living in the vibrant district of $u_{r, k}=\tilde{u}_{r}(s(v))-p c_{r, k}$ and a non-resident who lives at $w \in[0,1]$ receives an overall utility from visiting the vibrant city district of $u_{w, k}=\tilde{u}_{n r}(s(v))-t$. $w-p c_{n r, k}$. We assume that non-residents gain an alternative utility of zero when they do not visit the district. Thus, non-resident $w$ visits the district if $u_{w, k} \geq 0$. 
For the analysis of the different parking regimes $k$, we need the aggregate utilities. The residents receive an aggregate utility of

$$
U_{r, k}=r \cdot u_{r, k}=1 \cdot\left[\tilde{u}_{r}(s(v))-p c_{r, k}\right]
$$

and the visitors, and simultaneously all non-residents, of

$$
U_{n r, k}=\int_{0}^{v} u_{w, k} d w+\int_{v}^{1-v} 0=\tilde{u}_{n r}(s(v)) \cdot v-\frac{t}{2} \cdot v^{2}-p c_{n r, k} \cdot v .
$$

Adding up $U_{r, k}$ and $U_{n r, k}$ gives welfare

$$
W_{k}=\tilde{u}_{r}(s(v))-p c_{r, k}+\tilde{u}_{n r}(s(v)) \cdot v-\frac{t}{2} \cdot v^{2}-p c_{n r, k} \cdot v .
$$

\section{Parking Fees}

\section{A. Optimal Fees/Subsidies}

Optimal parking fees should both allocate on-street parking spaces to the group with the higher cost of using the parking lot and subsidize or tax the visitors to remedy the possible market failure of excess or insufficient entry. Thus, in a first best world, the parking fees ensure that the explained externalities of an additional visitor are taken into account. Suppose that under parking regime $k=p f$, the municipality charges the lump sum fees $f_{o}$ for on-street parking and $f_{l}$ for parking in the lot, which can be interpreted as subsides if they are negative. With regard to the cost of using the parking lot, we first consider case (a) that a resident bears a higher cost than a non-resident and proceed then with the reverse case (b).

In case (a), it is $c_{r}>c_{n r}$ and optimal when residents park on-street and visitors use the parking lot. Thus, the fees $f_{o}^{a}$ and $f_{l}^{a}$ have to ensure that (i) visitors prefer to park in the lot, (ii) residents prefer to park on-street and (iii) the pricing system leads to a number of visitors $v^{*}$ that maximizes welfare. Self-selection (i) is ensured if $p c_{n r, p f}^{a}=c_{n r}+f_{l}^{a}<f_{o}^{a}$ and self-selection (ii) if $p c_{r, p f}=f_{o}^{a} \leq c_{r}+f_{l}^{a}$, which implies that both (i) and (ii) are ensured if $f_{o}^{a}=c_{r}+f_{l}^{a}{ }^{4}$ Hence, the fee $f_{o}^{a}$ prevents the visit of an additional non-resident involving a negative externality in terms of an increased expected parking cost, as it is clear who parks where from the beginning. The fee (subsidy) $f_{l}^{a}$ that the visitors pay (receive) for parking in the lot should be used to ensure the optimal number of visitors $v^{*}$. The parking fees are expenditures for those who park in the district, but revenues for the municipality (or the converse) and therefore do not change welfare. In this case, welfare is

$$
W^{a}=\tilde{u}_{r}(s(v))+\tilde{u}_{n r}(s(v)) \cdot v-\frac{t}{2} \cdot v^{2}-c_{n r} \cdot v .
$$

\footnotetext{
${ }^{4}$ To keep the notation as simple as possible, we drop the index $p f$ in the following analysis of optimal parking fees for all relevant welfare measures.
} 
The optimal number of visitors $v^{*}$ is obtained when $d W^{a} / d v=0$, or when

$$
\left[\frac{d \tilde{u}_{r}}{d s}+v \cdot \frac{d \tilde{u}_{n r}}{d s}\right] \frac{d s}{d v}+\tilde{u}_{n r}(s(v))=t \cdot v+c_{n r} .
$$

However, the number of visitors can not be determined directly by a social planner, but results from the individual decisions of non-residents. Recall that nonresidents receive a zero alternative utility if they do not visit the district, thus non-resident $w \in[0,1]$ visits the district in case (a) if

$$
u_{w}^{a}=\tilde{u}_{n r}(s(v))-t \cdot w-p c_{n r}^{a}=\tilde{u}_{n r}(s(v))-t \cdot w-c_{n r}-f_{l}^{a} \geq 0 .
$$

For the indifferent non-resident $w=v$, who at the same time defines the total number of visitors, condition (10) is binding, so that

$$
f_{l}^{a}=\tilde{u}_{n r}(s(v))-t \cdot v-c_{n r}
$$

must hold. Inserting (9) to (11) yields

$$
f_{l}^{a}=-\left[\frac{d \tilde{u}_{r}\left(s\left(v^{*}\right)\right)}{d s}+v^{*} \cdot \frac{d \tilde{u}_{n r}\left(s\left(v^{*}\right)\right)}{d s}\right] \frac{d s\left(v^{*}\right)}{d v},
$$

which describes the negative parking fee or the parking subsidy that each nonresident receives when visiting the district and which is equivalent to the positive externality of the visitor who maximizes welfare. Thus, by subsidizing each visitor with $f_{l}^{a}$ and by charging each resident the fee $f_{o}^{a}=c_{r}+f_{l}^{a}$, the first best solution can be achieved.

If case (b) applies, thus $c_{r}<c_{n r}$ holds as suggested by van Ommeren, Wentink and Dekkers (2011), aggregate parking costs are minimized if visitors park onstreet and all on-street parking spaces are utilized. Therefore, the fees (or subsidies) $f_{o}^{b}$ and $f_{l}^{b}$ must induce (i) visitors to park on-street and (ii) residents to be indifferent between the two options. Self-selection is ensured if $p c_{n r}^{b}=f_{o}^{b}=$ $c_{r}+f_{l}^{b}=p c_{r}^{b}$, which looks similar to the self-selection condition in case (a), but here it implies that visitors park on-street instead of in the lot. The fee $f_{o}^{b}$ should be used to ensure the optimal number of visitors $v^{*}$. Welfare in this case is

$$
W^{b}=\tilde{u}_{r}(s(v))+\tilde{u}_{n r}(s(v)) \cdot v-\frac{t}{2} \cdot v^{2}-c_{r} \cdot v .
$$

The welfare functions $W^{a}$ and $W^{b}$, given by equations (8) and (13), are distinguished by the last term: in the case of $c_{r}>c_{n r}$, an additional visitor parks in the lot and therefore reduces welfare by $c_{n r}$ while he or she parks on-street in the case of $c_{r}<c_{n r}$ and thereby crowds out a resident who then uses the parking lot at the cost of $c_{r}$.

The optimal number of visitors $v^{*}$ is obtained when $d W^{b} / d v=0$, or when

$$
\frac{d W^{b}}{d v}=\left[\frac{d \tilde{u}_{r}}{d s}+v \cdot \frac{d \tilde{u}_{n r}}{d s}\right] \frac{d s}{d v}+\tilde{u}_{n r}(s(v))-c_{r}=t \cdot v .
$$

Again, whether or not a non-resident visits the district is his or her individual 
decision. In case (b), non-resident $w \in[0,1]$ gains an overall utility of

$$
u_{w}^{b}=\tilde{u}_{n r}(s(v))-t \cdot w-p c_{n r}^{b}=\tilde{u}_{n r}(s(v))-t \cdot w-f_{o}^{b}
$$

that is equal to zero for the indifferent visitor $w=v$. Thus,

$$
f_{o}^{b}=\tilde{u}_{n r}(s(v))-t \cdot v
$$

must hold and inserting (14) to (16) yields

$$
f_{o}^{b}=-\left[\frac{d \tilde{u}_{r}\left(s\left(v^{*}\right)\right)}{d s}+v^{*} \cdot \frac{d \tilde{u}_{n r}\left(s\left(v^{*}\right)\right)}{d s}\right] \frac{d s\left(v^{*}\right)}{d v}+c_{r}
$$

which is the optimal on-street parking fee (or subsidy). In this case, the fee that ensures $v^{*}$ not only comprises the positive, but also the negative externality of the visitor who maximizes welfare. Those of the residents who park in the lot receive $f_{l}^{b}=f_{o}^{b}-c_{r}$, and thus an amount of the positive externality the welfare-optimizing visitor causes by which their cost of parking in the lot is reduced.

\section{B. Discussion}

In our model, we assume that there are two homogeneous types of car driver (residents and visitors) and two parking possibilities (on-street and a parking lot) in the district. Therefore, second degree price discrimination is possible. In reality, however, such a parking regime may be difficult to implement. First of all, it is more likely that the visitors are heterogeneous with regard to both their preference for product variety and the cost of using the parking lot. Hence, it is almost impossible to efficiently tax/subsidize their visits by means of on- or off-street parking fees, especially when these are also used as an instrument for allocating the on-street parking spaces to drivers who incur the highest cost of using the parking lot. This objective becomes even more difficult to achieve if the residents are also heterogeneous regarding the cost of using the lot. Secondly, there could be more than only two parking possibilities in the district and its surroundings, all of which have different usage costs, so that minimizing them and ensuring an efficient number of customers from the outside is difficult or even impossible.

Moreover, as some of the parking fees are or may constitute parking subsidies, parking costs may become parking revenues for a driver and this might have undesired effects which require further regulation. For example, people from outside may visit the district without any intention to shop, but to earn the subsidy. Furthermore, if there were residents who had previously used their private parking space, they could now have an incentive to use public parking instead. More generally, car ownership could become more attractive for residents and therefore increase.

If the optimal on-street parking fees are positive, it is very likely that residents of downtown areas or other vibrant city districts would oppose such a policy in "their" neighborhood. Basically, of course, residents do not automatically acquire parking privileges in case the on-street parking capacity is public. Normally, however, the municipalities pursue parking polices whereby residents do not have to pay for parking, whether due to the residents' lobbying efforts or due to urban 
development measures.

As soon as municipalities confer special parking rights on residents, they pursue a residential parking policy. A policy that exempts residents from paying the parking fees, but that fulfills the two objectives - minimization of parking costs and ensuring an efficient number of visitors - is difficult to achieve. In case (a), selfselection (ii) may not work. Dependent on the magnitude of the parking subsidy that visitors receive for parking in the lot, it could also pay off for residents to park there. In case (b), self-selection (ii) only works if residents receive a subsidy equal to the cost of using the parking lot. Unless visitors can effectively be distinguished from residents, this subsidy has to be considered when determining the on-street parking fee that visitors face and that ensures self-selection (i). But then, this on-street fee may prevent the optimal number of visitors in the district.

\section{Residential Parking}

\section{A. Parking Regime}

Because of the difficulties associated with a residential parking policy according to which the municipality exempts residents from paying the parking fees, but tries to meet the two above mentioned objectives, we discuss a policy according to which the municipality reserves a certain share of on-street parking spaces exclusively for residents, but does not charge parking fees at all. In principle, the reservation of on-street parking spaces for residents minimizes the aggregate parking costs only if residents bear a higher cost of using the parking lot than nonresidents, that is if $c_{r}>c_{n r}$ holds, and if all on-street parking spaces are reserved for residents. This, however, implies the subsidization of non-resident visits, and subsidies can provoke undesired behavior. To encourage non-residents to visit the district without paying them a parking subsidy, it might be optimal to reserve some, but not all, on-street spaces for residents. However, in this case neither is the aggregate parking cost minimal, nor is the welfare-maximizing number of visitors ensured, so that such a residential parking policy is inevitably inferior to one that includes parking fees/subsidies for all parkers.

Recall that in the case of unregulated parking, the probability of finding a vacant on-street spot was $\rho=1 /(1+v)$. Rivalry in consumption emerged if $v>0$, so each member of both groups faced a $1-\rho>0$ probability of having to park in the parking lot. Under parking regime $k=r p$, the municipality assigns the share $\alpha \in[0,1]$ of on-street parking spaces to residential parking only. If $\alpha=0$, none of the on-street spaces are reserved for residents and if $\alpha=1$, all of the on-street spaces are reserved for residents. Thus, each resident has a probability of

$$
\rho_{r}=\frac{1-\alpha}{1+v}+\alpha=\frac{1+\alpha \cdot v}{1+v}
$$

to find a vacant on-street spot, whereas a non-resident who visits the district is able to park on-street with a probability of

$$
\rho_{n r}=\frac{1-\alpha}{1+v} .
$$


The probabilities of having to park in the lot are the converse probabilities $1-\rho_{r}$ and $1-\rho_{n r}$. Hence, each resident expects a parking cost of

$$
p c_{r}(v, \alpha)=c_{r} \cdot\left[1-\rho_{r}\right]=c_{r} \cdot \frac{v \cdot[1-\alpha]}{1+v}
$$

with

$$
\frac{\partial p c_{r}}{\partial v}=\frac{c_{r} \cdot[1-\alpha]}{[1+v]^{2}} \geq 0 \text { and } \frac{\partial p c_{r}}{\partial \alpha}=-\frac{c_{r} \cdot v}{1+v}<0,
$$

whereas each visitor of the district expects a parking cost of

$$
p c_{n r}(v, \alpha)=c_{n r} \cdot\left[1-\rho_{n r}\right]=c_{n r} \cdot \frac{v+\alpha}{1+v}
$$

with

$$
\frac{\partial p c_{n r}}{\partial v}=\frac{c_{n r} \cdot[1-\alpha]}{[1+v]^{2}} \geq 0 \text { and } \frac{\partial p c_{n r}}{\partial \alpha}=\frac{c_{n r}}{1+v}>0 .{ }^{5}
$$

\section{B. Equilibrium with Residential Parking}

We assume that each resident has a parking permit which indicates that he or she is entitled to park in the declared residential parking spaces. The permit is issued as soon as someone settles in the district and is free of charge. In reality, the fees for residential parking permits are very low. In Germany, for example, the fee for an annual parking permit is about $30 €$, implying a daily cost of about $0.08 €$, which is negligible. For the residents of Amsterdam, van Ommeren, Wentink and Dekkers (2011) find a marginal willingness to pay of $10 €$ per day for an onstreet parking permit. Thus, in theory, each of the homogeneous residents buys a parking permit if the fee does not exceed his or her willingness to pay. Possible expenditures for parking permits do not affect welfare, as they correspond to the revenues earned by the municipality and are returned in some way. If, however, the price of a parking permit exceeds each resident's willingness to pay, there is no demand for such permits and an allocation of parking spaces to residential parking does not occur, as unused allocations constitute a waste of space.

To calculate the optimal share of residential parking spaces $\alpha$, we first determine the equilibrium number of stores $s^{e}$ and visitors $v^{e}$ as a function of $\alpha$.

Under regime $r p$, a non-resident living at $w \in[0,1]$ gains an overall utility of $u_{w}=\tilde{u}_{n r}(s)-t \cdot w-p c_{n r}(v, \alpha)$. For the indifferent non-resident $w=v, u_{w}=0$ holds and defines a function $v(s)$ with

$$
\frac{d v}{d s}=-\frac{\partial u_{w} / \partial s_{\mid w=v}}{\partial u_{w} / \partial v_{\mid w=v}}=-\frac{d \tilde{u}_{n r} / d s}{-t-c_{n r} /[1+v]^{2}}>0 .
$$

Since $\tilde{u}_{n r}(0)=0$, a non-resident visits the district only if there is a positive number of stores. Furthermore, it is

$$
\frac{d^{2} v}{d s^{2}}=-\frac{\partial^{2} \tilde{u}_{n r} / \partial s^{2}}{-t-c_{n r} /[1+v]^{2}} \leq 0 .
$$

\footnotetext{
${ }^{5}$ Again, we drop the index $r p$ for all measures to keep the notation as simple as possible.
} 
Recall from Section I that the number of stores is given by

$$
s(v)=E^{-1}(\epsilon)=E^{-1}(p \cdot[1+v])
$$

with $d s / d v=p \cdot\left[E^{-1}\right]^{\prime}=p / E^{\prime}>0$ and $d^{2} s / d v^{2}=-p \cdot E^{\prime \prime} /\left[E^{\prime}\right]^{3} \leq 0$.

Let $\tilde{u}_{n r}\left(E^{-1}(p)\right)>\alpha \cdot c_{n r}$ and $\tilde{u}_{n r}\left(E^{-1}(2 p)\right)<t+c_{n r} \cdot[1+\alpha] / 2$. There is then an interior equilibrium $0<s^{e}$ and $0<v^{e}<1$. The first condition ensures that the buying power of the residents leads to such a variety that visiting the district pays off for at least some non-residents. The second condition ensures, due to the stores' cost of entry to the district, that the combined buying power of the residents and all non-residents does not result in a sufficient variety, that all non-residents consider the district worth visiting.

Figure 3 shows the visitors' free entry condition $u_{w}=0$, which is fulfilled if $v=v(s)$ and the stores' free entry condition $\Pi=0$, which is fulfilled if $s=s(v)$. The intersection of $v(s)$ and $s(v)$ determines the equilibrium number of visitors $v^{e}$ and of stores $s^{e}$.

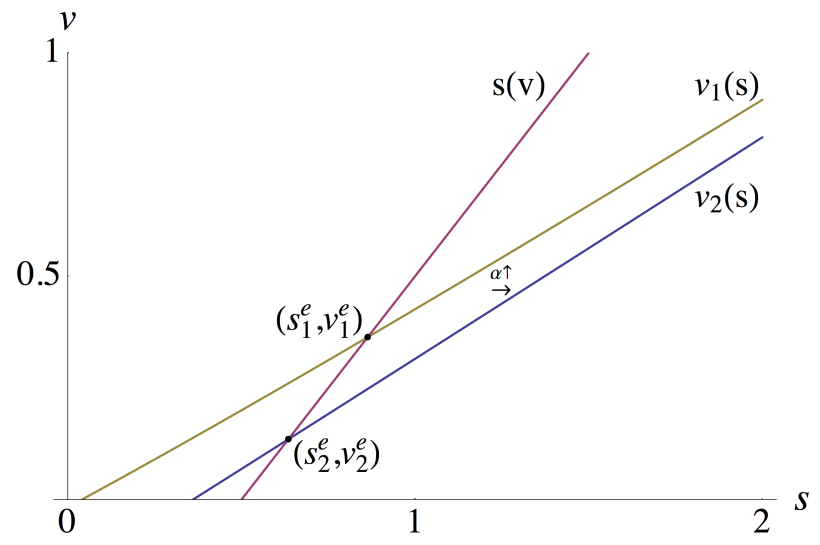

Figure 3. Free ENTRY EQUILIBRIUM

Note: The figure with its three graphs is based on the results of our numerical example in Section III.E. To be more specific, we set $c_{n r}=1 / 5$. Furthermore, we set $\alpha=1 / 10$ to get $v_{1}(s)$ and $\alpha=9 / 10$ to get $v_{2}(s)$. The behavior of $s(v)$ results directly from our assumptions in the example. However, the behavior of $v(s)$ and $s(v)$ also holds in general.

At equilibrium, $v^{e}$ and $s^{e}$ depend on different parameters like the parameter that indicates the residents' and non-residents' valuation of the product variety, the per-unit travel cost, the cost that non-residents incur when they have to use the parking lot and the specific entry cost incurred by each store. Since we focus on a residential parking policy that assigns on-street parking spaces to residential parking only, we treat all these exogenous parameters as constant, except $\alpha \in[0,1]$. Thus, we define the equilibrium number of visitors as a function $v^{e}(\alpha)$ and the equilibrium number of stores as a function $s^{e}(\alpha)$.

We use the condition $u_{w}=\tilde{u}_{n r}(s)-t \cdot w-p c_{n r}(v, \alpha)=0$ for the indifferent 
non-resident $w=v$ to calculate

$$
\frac{d v}{d \alpha}=-\frac{\partial u_{w} / \partial \alpha_{\mid w=v}}{\partial u_{w} / \partial v_{\mid w=v}}=-\frac{-c_{n r} /[1+v]}{-t-c_{n r} /[1+v]^{2}}=-\frac{c_{n r} \cdot[v+1]}{c_{n r}+t \cdot[v+1]^{2}}<0 .
$$

The sign of equation (24) entails a downward shift of $v(s)$, as shown in Figure 3. Because $\partial \Pi / \partial \alpha=0, s(v)$ does not shift, thus

$$
\frac{d v^{e}}{d \alpha}<0
$$

holds. In the following analysis, we assume $-1<d v^{e} / d \alpha<0$. Since $d s / d v>0$, it follows that

$$
\frac{d s^{e}}{d \alpha}<0
$$

At the free entry equilibrium, non-resident $w \in[0,1]$, who visits the district, receives an overall utility of

$$
u_{w}^{e}=\tilde{u}_{n r}^{e}\left(s^{e}(\alpha)\right)-t \cdot w-p c_{n r}^{e}\left(v^{e}(\alpha), \alpha\right)=\tilde{u}_{n r}^{e}\left(s^{e}(\alpha)\right)-t \cdot w-\frac{c_{n r} \cdot\left[\alpha+v^{e}(\alpha)\right]}{1+v^{e}(\alpha)}
$$

and each resident receives a utility of

$$
u_{r}^{e}=\tilde{u}_{r}^{e}\left(s^{e}(\alpha)\right)-p c_{r}^{e}\left(v^{e}(\alpha), \alpha\right)=\tilde{u}_{r}^{e}\left(s^{e}(\alpha)\right)-\frac{c_{r} \cdot[1-\alpha] \cdot v^{e}(\alpha)}{1+v^{e}(\alpha)} .
$$

LEMMA 1: If the share of residential parking spaces increases, both the residents' and non-residents' utility from product variety decreases as the number of stores declines; thus it is

$$
\frac{d \tilde{u}_{j}^{e}}{d \alpha}=\frac{d \tilde{u}_{j}^{e}}{d s^{e}} \frac{d s^{e}}{d \alpha}<0 \text { with } j=r, n r .
$$

Furthermore, an increase in the share of residential parking spaces results in an increase in the parking cost a non-resident expects,

$$
\frac{d p c_{n r}^{e}}{d \alpha}=\frac{\partial p c_{n r}^{e}}{\partial v^{e}} \frac{d v^{e}}{d \alpha}+\frac{\partial p c_{n r}^{e}}{\partial \alpha}=\frac{c_{n r} \cdot\left[[1-\alpha] v^{e \prime}(\alpha)+v^{e}(\alpha)+1\right]}{\left[1+v^{e}(\alpha)\right]^{2}}>0,
$$

but to a decrease in the parking cost a resident expects,

$$
\frac{d p c_{r}^{e}}{d \alpha}=\frac{\partial p c_{r}^{e}}{\partial v^{e}} \frac{d v^{e}}{d \alpha}+\frac{\partial p c_{r}^{e}}{\partial \alpha}=-\frac{c_{r} \cdot\left[v^{e}(\alpha)+v^{e}(\alpha)^{2}-[1-\alpha] v^{e \prime}(\alpha)\right]}{\left[1+v^{e}(\alpha)\right]^{2}}<0 .
$$




\section{Welfare Analysis}

In the case of parking regime $r p$, welfare is

$$
\begin{aligned}
W^{e} & =\tilde{u}_{r}^{e}\left(s^{e}(\alpha)\right)-p c_{r}^{e}\left(v^{e}(\alpha), \alpha\right) \\
& +\tilde{u}_{n r}^{e}\left(s^{e}(\alpha)\right) \cdot v^{e}(\alpha)-\frac{t}{2} \cdot\left[v^{e}(\alpha)\right]^{2}-p c_{n r}^{e}\left(v^{e}(\alpha), \alpha\right) \cdot v^{e}(\alpha)
\end{aligned}
$$

To find the optimal share of residential parking spaces $\alpha^{*}$, we derive $W^{e}$ with respect to $\alpha$ and obtain, after some rearrangements,

$$
\begin{aligned}
\frac{d W^{e}}{d \alpha} & =\frac{d \tilde{u}_{r}^{e}}{d s^{e}} \frac{d s^{e}}{d \alpha}-\frac{\partial p c_{r}^{e}}{\partial v^{e}} \frac{d v^{e}}{d \alpha}-\frac{\partial p c_{r}^{e}}{\partial \alpha}+v^{e} \cdot\left[\frac{d \tilde{u}_{n r}^{e}}{d s^{e}} \frac{d s^{e}}{d \alpha}-\frac{\partial p c_{n r}^{e}}{\partial v^{e}} \frac{d v^{e}}{d \alpha}-\frac{\partial p c_{n r, r p}^{e}}{\partial \alpha}\right] \\
& +\frac{d v^{e}}{d \alpha} \cdot\left[\tilde{u}_{n r}^{e}-t \cdot v^{e}-p c_{n r}^{e}\right] .
\end{aligned}
$$

The term $\left[\tilde{u}_{n r}^{e}-t \cdot v^{e}-p c_{n r}^{e}\right]$ describes the marginal visitor's utility which equals zero at the visitor's optimum. Thus, we find

$$
\begin{aligned}
\frac{d W^{e}}{d \alpha} & =\frac{d \tilde{u}_{r}^{e}}{d s^{e}} \frac{d s^{e}}{d \alpha}-\frac{\partial p c_{r}^{e}}{\partial v^{e}} \frac{d v^{e}}{d \alpha}-\frac{\partial p c_{r}^{e}}{\partial \alpha}+v^{e} \cdot\left[\frac{d \tilde{u}_{n r}^{e}}{d s^{e}} \frac{d s^{e}}{d \alpha}-\frac{\partial p c_{n r}^{e}}{\partial v^{e}} \frac{d v^{e}}{d \alpha}-\frac{\partial p c_{n r}^{e}}{\partial \alpha}\right] \\
& =\frac{d \tilde{u}_{r}^{e}}{d \alpha}-\frac{d p c_{r}^{e}}{d \alpha}+v^{e} \cdot\left[\frac{d \tilde{u}_{n r}^{e}}{d \alpha}-\frac{d p c_{n r}^{e}}{d \alpha}\right]
\end{aligned}
$$

which we set equal to zero.

PROPOSITION 1: The optimal share of residential parking spaces $\alpha^{*}$ is found when the decrease in both the residents' and visitors' utility from product variety equals the savings in overall parking cost; thus when

$$
\frac{d \tilde{u}_{r}^{e}}{d \alpha}+v^{e} \cdot \frac{d \tilde{u}_{n r}^{e}}{d \alpha}=\frac{d p c_{r}^{e}}{d \alpha}+v^{e} \cdot \frac{d p c_{n r}^{e}}{d \alpha}
$$

To actually realize savings in overall expected parking cost,

$$
\frac{d p c_{r}^{e}}{d \alpha}+v^{e} \cdot \frac{d p c_{n r}^{e}}{d \alpha}=\frac{v^{e \prime}(\alpha)\left[c_{r}+c_{n r} \cdot v^{e}(\alpha)\right][1-\alpha]}{\left[1+v^{e}(\alpha)\right]^{2}}+\frac{\left[c_{n r}-c_{r}\right] \cdot v^{e}(\alpha)}{1+v^{e}(\alpha)}
$$

has to be negative, which is only possible if

$$
\frac{c_{r}}{c_{n r}}>\left[1+\frac{\left[1+v^{e}(\alpha)\right] \cdot v^{e \prime}(\alpha) \cdot[1-\alpha]}{v^{e}(\alpha)\left[1+v^{e}(\alpha)\right]-v^{e \prime}(\alpha)[1-\alpha]}\right]
$$

Thus, inequality (36) defines a necessary condition for a positive share of residential parking spaces to be optimal. Because the right side of (36) is less than one, visitors may bear a somewhat lower parking cost in the outside lot than residents. Note, however, that (36) is not sufficient for residential parking to be welfare-enhancing, since it yet does not ensure that $d W^{e} / d \alpha$ is positive. 


\section{Local Decision-Making}

In reality, decisions on parking regulations are normally made at a local level (Arnott, 2011). Business owners may oppose regulations that prevent potential customers from visiting the district. In our model, however, we assume that business owners are non-residents and that businesses are perfectly mobile. We thus omit business lobbying efforts in the analysis. As residents are assumed to be homogeneous, individual preferences equal collective preferences. Thus, we simply derive $U_{r}^{e}=1 \cdot\left[\tilde{u}_{r}^{e}\left(s^{e}(\alpha)\right)-p c_{r}^{e}\left(v^{e}(\alpha), \alpha\right)\right]$ with respect to $\alpha$ and set it equal to zero in order to determine the preferred share of residential parking spaces. Because

$$
\frac{d U_{r}^{e}}{d \alpha}=\frac{\partial \tilde{u}_{r}^{e}}{\partial s^{e}} \frac{d s^{e}}{d \alpha}-\frac{\partial p c_{r}^{e}}{\partial v^{e}} \frac{d v^{e}}{d \alpha}-\frac{\partial p c_{r}^{e}}{\partial \alpha}=\frac{d \tilde{u}_{r}^{e}}{d \alpha}-\frac{d p c_{r}^{e}}{d \alpha} \stackrel{!}{=} 0
$$

the optimal share of residential parking spaces from the resident perspective $\alpha_{r}^{*}$ is found when the decrease in the residents' utility from product variety equals the residents' savings in expected parking cost; thus when

$$
\frac{d \tilde{u}_{r}^{e}}{d \alpha}=\frac{d p c_{r}^{e}}{d \alpha} .
$$

Even if there is a ballot and both residents and visitors are entitled to vote, one of the residents is the median voter and, according to the median voter theorem, $\alpha_{r}^{*}$ is the adopted policy.

PROPOSITION 2: If local authorities only consider the preferences of the district's residents, but ignore the preferences of non-residents as potential visitors when deciding on residential parking, or if there is a ballot on this issue, the resulting share of residential parking spaces exceeds the welfare-optimizing share, i.e. $\alpha_{r}^{*}>\alpha^{*}$, whenever the welfare-optimizing share of residential parking spaces is positive, but less than one.

Proof: See appendix.

Residents prefer a higher share of on-street parking spaces to be reserved for them than is optimal from the welfare perspective, because they ignore the negative effects of their decision on the overall visitors' utility in terms of a lower utility from product variety and a higher expected parking cost.

\section{E. A numerical example}

The following example illustrates our general results. We assume that residents and non-residents share the same preference for product variety. More precisely, $\tilde{u}_{r}(s)=\tilde{u}_{n r}(s)=[\mu-p] \cdot s$. Recall that the price each store charges its customers is given exogenously. We assume that it is $p=1 / 2$. Furthermore, we set $\mu=1$, so that $\tilde{u}_{r}(s)=\tilde{u}_{n r}(s)=s / 2$. The per-unit travel cost a non-resident incurs when visiting the district is $t=1$. Altogether, it follows that

$$
u_{r}=\tilde{u}_{r}(s)-p c_{r}(v, \alpha)=\frac{1}{2} \cdot s-\frac{c_{r} \cdot[1-\alpha] \cdot v}{1+v}
$$


and

$$
u_{w}=\tilde{u}_{n r}(s)-t \cdot w-p c_{n r}(v, \alpha)=\frac{1}{2} \cdot s-w-\frac{c_{n r} \cdot[v+\alpha]}{1+v} .
$$

Non-resident $w \in[0,1]$ visits the district if $u_{w} \geq 0$. We assume that $0<c_{n r}<1 / 4$, which implies that even some non-residents visit the district if all on-street spaces are assigned to residential parking. For the indifferent non-resident $w=v, u_{w}=0$ holds, so that the number of visitors as a function of the number of stores is

$$
v(s)=\frac{s+\sqrt{\left[s-2-2 c_{n r}\right]^{2}+8 \cdot\left[s-2 c_{n r} \alpha\right]}-2-2 c_{n r}}{4} .
$$

With regard to the entry cost that each store incurs, we assume $E(s)=e \cdot s$ with $e=1$, which defines

$$
s(v)=\frac{1}{2} \cdot[1+v]
$$

Both $v(s)$ and $s(v)$ are shown in Figure 3 for $c_{n r}=1 / 5$ and $\alpha=1 / 10$, as well as $c_{n r}=1 / 5$ and $\alpha=9 / 10$. Inserting (41) to (42) yields the equilibrium number of stores

$$
s^{e}=s^{e}(\alpha)=\frac{\sqrt{1+c_{n r}+c_{n r}^{2}-3 c_{n r} \alpha}+1-c_{n r}}{3}
$$

and inserting (43) then to (41) yields the equilibrium number of visitors

$$
v^{e}=v^{e}(\alpha)=\frac{2 \sqrt{1+c_{n r}+c_{n r}^{2}-3 c_{n r} \alpha}-1-2 c_{n r}}{3},
$$

also shown in Figure 3.

With the explicit results for $s^{e}$ and $v^{e}$, we can determine the explicit expressions for $\tilde{u}_{j}^{e}\left(s^{e}\right)$ and $p c_{j}^{e}\left(v^{e}, \alpha\right)$ with $j=r, n r$, and thus for $d W^{e} / d \alpha$ and $d U_{r}^{e} / d \alpha$ (see equations (33) and (37)). Solving $d W^{e} / d \alpha=0$ for $\alpha$ yields

$$
\alpha=\frac{c_{n r}^{2}\left[21+16 c_{n r}\right]+3 c_{r}^{2}\left[7+16 c_{n r} \cdot\left[1+c_{n r}\right]\right]-2 c_{r} c_{n r}\left[29+8 c_{n r}\left[1+4 c_{n r}\right]\right]}{\left.16\left[3 c_{r}-2 c_{n r}\right)\right]^{2} c_{n r}} .
$$

Thus, the welfare-optimizing share of residential parking spaces is

$$
\alpha^{*}\left(c_{r}, c_{n r}\right)= \begin{cases}0 & \text { if } c_{r} \leq \underline{c} \\ \alpha & \text { if } \underline{c}<c_{r}<\bar{c} \\ 1 & \text { if } c_{r} \geq \bar{c}\end{cases}
$$

with

$\underline{c}=\frac{c_{n r}\left[29+\left[20-32 c_{n r}\right] \sqrt{1+c_{n r}+c_{n r}^{2}}+8 c_{n r}\left[1+4 c_{n r}\right]\right]}{21+48 c_{n r}\left[1+c_{n r}\right]}$ and $\bar{c}=\frac{16 c_{n r}^{2}-7 c_{n r}}{12 c_{n r}-3}$. 
If the decision on the share of residential parking spaces is made at a local level, we simply have to solve $d U_{r}^{e} / d \alpha=0$ for $\alpha$. We obtain an optimal share of residential parking spaces from the resident perspective of

$$
\alpha_{r}^{*}\left(c_{r}, c_{w}\right)= \begin{cases}\left(16+7 / c_{n r}+16 c_{n r}-\left(6 c_{r}+c_{n r}\right) / c_{r}^{2}\right) / 48 & \text { if } c_{r} \leq \tilde{c} \\ 1 & \text { if } c_{r}>\tilde{c} .\end{cases}
$$

with $\tilde{c}=c_{n r} /\left[1-4 c_{n r}\right]$.

Figure 4 depicts our results for $\alpha^{*}$ and $\alpha_{r}^{*}$ when $c_{n r}=1 / 8$. If $c_{r}<\underline{c}$, assigning some, but not all on-street parking spaces to residential parking is only optimal from the resident perspective. If $\underline{c}<c_{r}<\tilde{c}$, however, a social planner also would assign some, but not all of the on-street spaces to residential parking, albeit fewer than the residents would do. From the resident perspective, exclusive residential parking in on-street spaces is optimal if $\tilde{c}<c_{r}$, whereas a share of residential parking spaces smaller than one is welfare-optimizing as long as $c_{r}<\bar{c}$. Only if $\bar{c} \leq c_{r}$, would a social planner also assign all on-street parking spaces to residential parking.

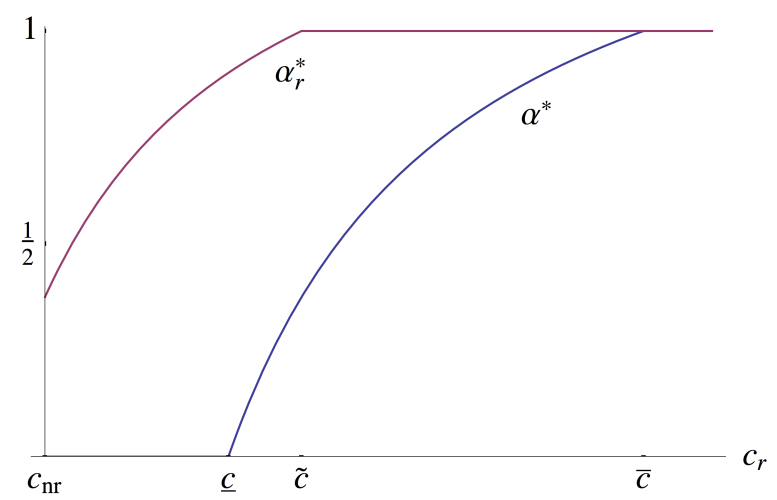

Figure 4. Optimal Shares OF Residential PARKing SPACES

In our example, we assumed that residents and non-residents have homogeneous preferences for product variety, for which we used a numerical description. As a result, the optimal shares of residential parking spaces seem to be independent of this preference. To show that this is not the case, we allow for the case that residents and non-residents differ in their preferences for product variety. We still assume that $\tilde{u}_{n r}=[\mu-p] \cdot s=[1-1 / 2] \cdot s$, but for the utility a resident derives from product variety, we assume $\tilde{u}_{r}=[\lambda-p] \cdot s=[\lambda-1 / 2] \cdot s$ with $\lambda \geq \mu=1$. Thus, the utility a resident receives from product variety is at least as high as that obtained by a non-resident who visits the district. The calculations of the equilibrium values are as usual, the only difference being that some of them contain the variable $\lambda$, as the residents' aggregate overall utility and welfare. Solving $d W^{e} / d \alpha=0$ for $\alpha$ in this case yields

$$
\begin{aligned}
\alpha & =\frac{\left[5-16 c_{n r}\right] c_{n r}^{2}-2 c_{n r}\left[11+8 c_{n r}\left[1+4 c_{n r}\right]\right] c_{r}+3\left[7+16 c_{n r}\left[1+c_{n r}\right]\right] c_{r}^{2}}{16 c_{n r}\left[2 c_{n r}-3 c_{r}\right]^{2}} \\
& +\frac{\left[c_{n r}\left[7+8 c_{n r}-3 \lambda\right]-9 c_{r}\right] \lambda}{4\left[2 c_{n r}-3 c_{r}\right]^{2}}
\end{aligned}
$$


with

$$
\frac{d \alpha}{d \lambda}=\frac{c_{n r}\left[7+8 c_{n r}-6 \lambda\right]-9 c_{r}}{4\left[2 c_{n r}-3 c_{r}\right]^{2}}<0,
$$

at least for $c_{r} \geq c_{n r}$. From the sign of equation (49), we can deduce that the optimal share of residential parking spaces from the welfare perspective is the lower the more the residents value the variety offered in their neighborhood. The same relationship of course applies for the optimal share of residential parking spaces from the resident perspective, as the variable $\lambda$ is part of a resident's utility. We can further infer that there is also a negative relationship between the non-residents' (gross) utility from variety $\mu$ and the optimal share of residential parking spaces from the welfare (but not the resident) perspective.

\section{Conclusion}

Many cities provide residential parking permits for residents who live in downtown areas and in other city districts where on-street parking capacity is scarce. These permits either allow residents to park for free anywhere in their own neighborhood while non-residents pay for parking, or allow residents to park in onstreet spaces that are reserved for their exclusive use. Within the context of a formal model of a vibrant city district whose residents and visitors appreciate the product variety offered, but might experience inefficiently high parking costs, we focused on the latter alternative and analyzed the trade-off between the moreconvenient-parking effect on the residents' side, due to residential parking, and the loss-of-variety effect, due to fewer shoppers coming from outside the district. We determined the share of residential parking spaces that is optimal both from a welfare and from the resident perspective, and found that if the decision is made locally, more than welfare-optimal parking spaces are assigned to residential parking. This possible latter result is problematic insofar as the discussed residential parking policy is already not the first best solution with regard to parking cost minimization and ensuring an efficient number of non-resident shoppers. A first best solution includes price-discriminated parking fees (or subsidies), but might be difficult to implement.

In this study, we assumed that the provision of on- and off-street parking capacity does not entail any cost and that drivers do not cruise for a parking spot. An important extension of our residential parking analysis would relax these assumptions. With regard to negative cruising externalizes, the first best solution can provide a remedy, whereas a policy of reserving a share of on-street parking spaces for residents is likely to exacerbate the problem.

A further and ambitious approach for future research would entail a public choice analysis, including political lobbying. We assumed that retail stores, restaurants and other businesses are perfectly mobile and therefore indifferent to parking regulations that may have a negative effect on the visits of non-resident customers. This assumption rarely holds in reality and therefore, businesses do normally oppose residential parking. Thus, the resulting parking regime depends on the institutional design that the city or city district municipality uses to determine its parking policy. 


\section{REFERENCES}

Anderson, Simon P., and Andre de Palma. 2004. "The economics of pricing parking." Journal of Urban Economics, 55: 1-20.

Arnott, Richard. 2011. "Parking economics." In A Handbook of Transport Economics. , ed. Andre de Palma, Robin Lindsey, Emile Quinet and Roger Vickerman, Chapter 31, 726-743. Edward Elgar.

Arnott, Richard, and Eren Inci. 2006. "An integrated model of downtown parking and traffic congestion." Journal of Urban Economics, 60: 418-442.

Arnott, Richard, and John Rowse. 2009. "Downtown parking in auto city." Regional Science and Urban Economics, 39: 1-14.

Arnott, Richard, and Jown Rowse. 1999. "Modeling Parking." Journal of Urban Economics, 45: 97-124.

Calthrop, E., and S. Proost. 2006. "Regulating on-street parking." Regional Science and Urban Economics, 36: 29-48.

Glazer, Amihai, and Esko Niskanen. 1992. "Parking fees and congestion." Regional Science and Urban Economics, 22: 123-132.

Shoup, Donald. 1999. "The trouble with minimum parking requirements." Transportation Research Part A, 33: 549-574.

Shoup, Donald. 2005. The high cost of free parking. Planners Press.

Still, Ben, and David Simmonds. 2000. "Parking restraint policy and urban vitality." Transport Reviews, 20(3): 291-316.

van Ommeren, Jos N., Derk Wentink, and Jasper Dekkers. 2011. "The real price of parking policy." Journal of Urban Economics, 70: 25-31.

van Ommeren, Jos N., Derk Wentink, and Piet Rietveld. 2012. "Empirical evidence on cruising for parking." Transportation Research Part A, 46: 123130.

Willson, Richard W. 1995. "Suburban parking requirements: a tacit policy for automobile use and urban sprawl." Journal of the American Planning Association, 61(1): 29-42. 


\section{Mathematical Appendix}

Proof of Proposition 2

To prove $\alpha^{*} \leq \alpha_{r}^{*}$, where $\alpha^{*}=\alpha_{r}^{*}$ is only possible if $\alpha^{*}=0$ or $\alpha^{*}=1$, it is sufficient to show $d W^{e} / d \alpha<d U_{r}^{e} / d \alpha$ for $\alpha \in(0,1)$. Using solutions (33) for $d W^{e} / d \alpha$ and (37) for $d U_{r}^{e} / d \alpha$, respectively, it holds that $d W^{e} / d \alpha<d U_{r}^{e} / d \alpha$ if and only if

(A1) $v^{e}\left[\frac{d \tilde{u}_{n r}^{e}}{d \alpha}-\frac{d p c_{n r}^{e}}{d \alpha}\right]=v^{e} \cdot\left[\frac{d \tilde{u}_{n r}^{e}}{d \alpha}-\frac{c_{n r} \cdot\left[[1-\alpha] v^{e \prime}(\alpha)+v^{e}(\alpha)+1\right]}{\left[1+v^{e}(\alpha)\right)^{2}}\right]<0$.

Recall from Lemma 1 that $d \tilde{u}_{n r}^{e} / d \alpha<0$ and $d p c_{n r}^{e} / d \alpha>0$ hold in our analysis. Accordingly, the sign of the term in brackets of (A1) is negative. $v^{e}>0$ and thus $d W^{e} / d \alpha<d U_{r}^{e} / d \alpha$ holds for all $\alpha \in(0,1)$. 
Westfälische Wilhelms-Universität Münster, Institute of Transport Economics, Working Paper Series

12 "Specific Investments and Ownership Structures in Railways - An Experimental Analysis"

by Thomas Ehrmann/ Karl-Hans Hartwig/ Torsten Marner/ Hendrik Schmale, 2009

13 "Größenvorteile im deutschen ÖSPV - Eine empirische Analyse“ by Karl-Hans Hartwig/ Raimund Scheffler, 2009

14 "Measuring Efficiency of German Public Bus Transport“ by Raimund Scheffler/ Karl-Hans Hartwig/ Robert Malina, July 2010

15 „Market Power of Hub Airports: The Role of Lock-in Effects and Downstream Competition“

by Florian Allroggen/ Robert Malina, July 2010

16 "Studentische Automobilnutzung - mangels Alternativen?" by Daniel Krimphoff/ Peter Pollmeier, November 2011

17 „Ein Ansatz zur Verteilung der Bestellerentgelte im SPNV“ by Karl-Hans Hartwig/ Peter Pollmeier, September 2012

18 "Residential Parking in Vibrant City Districts" by Inga Molenda and Gernot Sieg, September 2013

19 "Are commercial ceilings adequate for the regulation of commercial overload on free-to-air TV channels?" by Julia Rothbauer and Gernot Sieg, September 2013

For a complete list of Working Papers published by Westfälische Wilhelms-Universität Münster, Institute of Transport Economics, please visit the website (http://www.ivmuenster.de) 
= 